\title{
Alain Tarrius et Olivier Bernet « Migrants internationaux et nouveaux réseaux criminels »
}

Éditions Trabucaire, 2010, 162 pagesISBN : 978-2-84974-112-2

\section{OpenEdition}

Journals

Édition électronique

URL : http://journals.openedition.org/transcontinentales/185

DOI : $10.4000 /$ transcontinentales. 185

ISBN : 978-2-7351-1557-0

ISSN : 1775-397X

Éditeur

Editions de la maison des sciences de l'homme

Édition imprimée

Date de publication : 31 décembre 2010

ISSN : 1950-1684

Référence électronique

" Alain Tarrius et Olivier Bernet « Migrants internationaux et nouveaux réseaux criminels » »,

Transcontinentales [En ligne], 8/9 | 2010, mis en ligne le 03 février 2011, consulté le 07 septembre 2020. URL : http://journals.openedition.org/transcontinentales/185 ; DOI : https://doi.org/10.4000/ transcontinentales. 185

Ce document a été généré automatiquement le 7 septembre 2020

Tous droits réservés 


\section{Alain Tarrius et Olivier Bernet « Migrants internationaux et nouveaux réseaux criminels »}

Éditions Trabucaire, 2010, 162 pagesISBN : 978-2-84974-112-2

NOTE DE L'ÉDITEUR

Alain Tarrius est professeur à l'université de Toulouse-Le Mirail. Membre des laboratoires Cnrs : Lisst-Cers à Toulouse et Migrinter à Poitiers.

Olivier Bernet est chargé de cours à l'université de Toulouse-Le Mirail, formateur en travail social et membre associé du laboratoire Cnrs : Lisst-Cers à Toulouse. 
1 Environ soixante mille migrants afghans passent annuellement par les ports turcs et géorgiens de la mer Noire: là, ils se chargent de produits électroniques en provenance du Sud-Est asiatique transitant par Dubaï et Koweït City. Totalement détaxés, ces articles sont livrés en Bulgarie, c'est-à-dire dans la Communauté européenne, à $40 \%$ de leur prix de vente européen. Environ six milliards de dollars de marchandises franchissent ainsi cette frontière. Les «transmigrants» afghans retournent ensuite chez eux.

2 Les régulations des échanges bancaires liées à la crise interdisent désormais à ces migrants, auxiliaires des stratégies commerciales du poor to poor, «l'entre-

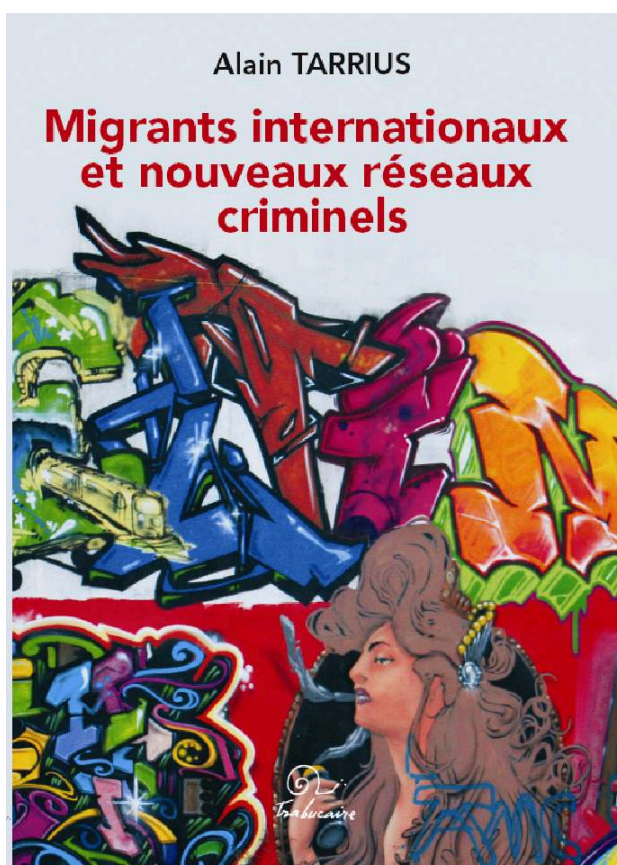
pauvres» des grandes firmes contournement des règles de l'OMc et détaxe des produits devenus ainsi, en entrée de gamme, accessibles au plus grand nombre -, de bénéficier de lignes internationales de crédit que des banques émirates leur consentaient. Alors, des réseaux criminels suppléent à cette " moralisation » des circulations de capitaux en offrant des sommes équivalentes d'argent à blanchir et, en contrepartie, en exigeant des Afghans qu'ils cultivent, pendant leurs migrations, le pavot à opium en Turquie et en Géorgie.

3 En somme, des dizaines de milliers d'Afghans se trouvent contraints de participer aux activités de réseaux criminels et y associent, de fait, des grandes firmes de l'électronique asiatique. Ces nouvelles accointances, étendues aux populations balkaniques, fournissent une main-d'œuvre afghane et albanaise aux entreprises sud italiennes pratiquant le blanchiment du même argent sale. Ce phénomène est accompagné d'un regain des migrations féminines contraintes pour la prostitution, à partir des Balkans, du Caucase et du pourtour méditerranéen vers les «clubs » du Levant espagnol, via Naples, Bari, Brindisi. De la Junquera à Malaga, la "passe » se négocie désormais avec une dose de cocaïne. La Junquera, lieu d'entrée privilégié, associe aux revenus de ces activités quelques notables résidant de part et d'autre de la frontière et, surtout, de Perpignan à Barcelone.

Un nouvel ordre criminel se déploie, associant les "pieuvres » locales dans une toile mondiale, proche du modèle Internet, alors que les États peinent à définir leur place dans cette insaisissable mondialisation.

Les chercheurs nous font vivre de l'intérieur ces transformations au plus près des terrains qu'ils explorent depuis des années. 